\title{
Evaluation of paediatric intensive care in a regional centre
}

\author{
J McAloon, P Crean, J Jenkins, G McClure
}

\begin{abstract}
All 162 consecutive admissions to a multidisciplinary paediatric intensive care unit in the UK have been prospectively evaluated in terms of therapeutic intention, sickness levels, age, utilisation of resources, and outcome. For $101(62.3 \%)$ of the children admitted the aim of treatment was to cure the condition but for $30(18.5 \%)$ ultimately only a palliative option was available. Five children were admitted to avail of specialised monitoring facilities. One half of the children admitted were physiologically unstable. The majority $(102,62.9 \%) \cdot$ were age 12 months or less. Resource utilisation, which was not affected by therapeutic intention, was greatest for the sickest patients, those age 1 month or less and non-survivors. Mortality rate overall was $17 \cdot 9 \%$. Mortality was unaffected by age and therapeutic intention and was inversely related to level of sickness.

The information provided by this study forms a basis for medical audit within the unit and is essential for meaningful comparisons of standards of care and outcome with other units.
\end{abstract}

Paediatric intensive care has developed as a unique specialty in the past 20 years. Guidelines exist for the facilities, organisation, staffing, and training required for this service. ${ }^{1-3}$ Although the provision of paediatric intensive care is expensive, accounting for $20 \%$ of the hospital bill, ${ }^{2}$ detailed evaluation has not been undertaken in the UK and there is also only limited European data available. ${ }^{4}$ Deficiency of this information will inhibit further development of paediatric intensive care.

Consequently this study has been undertaken to document admission criteria, sickness levels, resource utilisation, and outcome of patients diatric intensive care unit.

Intensive Care Unit, Royal Belfast Hospital for Sick Children J McAloon P Crean J Jenkins

Department of Child Health, Queen's University, Belfast

G McClure

Correspondence to: Dr J McAloon, Paediatric Department, Waveney Hospital, Ballymena, Northern Ireland BT43 6HR.

Accepted 22 May 1991

Patients and methods

Northern Ireland has a population of 1.6 million people, most of whom live in rural or semirural areas. Belfast is the only sizable city and no part of the province is more than 100 miles from Belfast by road. As there is a good network of roads throughout the province this means that two hours is the maximum time taken to transport any sick child to the paediatric intensive care unit in the Royal Belfast Hospital for Sick Children. This six bedded unit, opened in 1970, provides a comprehensive intensive admitted to a multidisciplinary, regional pae-

care service, admitting neonates with surgical problems, neonates with respiratory disease if beds in the special care baby unit are not available, and infants and children with medical and surgical illnesses (table 1).

All consecutive admissions over an eight month period were prospectively studied. On admission patients were classified according to age, Clinical Classification System, ${ }^{6}$ and management goals.

The Clinical Classification System provides a method of qualitatively assessing care requirements and correlates well with quantitative measures of sickness. ${ }^{7-9}$ Four classes of patients are defined. Class 1 patients are hospitalised patients not requiring intensive care unit facilities. Class 2 patients need the observation capabilities of the intensive care unit and the class 3 group, although physiologically stable, require intensive nursing care. Class 4 patients are physiologically unstable and require frequent medical and nursing interventions.

Four management categories were considered possible for each individual. ${ }^{10}$ If the treatment intention was definitive the management was described as 'curative', an example being a child treated for meningococcaemia. If the patient's condition could ultimately be cured but the current treatment was not definitive the goal category was 'palliative option'. If no definitive treatment was foreseeable at any stage the category was 'palliative no option'. For example, each neonate undergoing the first step of staged correction of oesophageal atresia was allocated to the palliative option group and any child with the Arnold-Chiari malformation having a ventricular shunt revised was allocated to the palliative no option group. The fourth group of children, admitted solely for specialised monitoring, was designated as 'monitored'.

The severity of illness was evaluated for all children using the Therapeutic Intervention Scoring System (TISS), ${ }^{11}{ }^{12}$ which was first scored from admission time to 12 noon (admission score) and for each subsequent 24 hour period for the duration of stay. The TISS quantifies 72 therapeutic options available in the paediatric

Table 1 Primary specialty service responsible for admission $(n=162)$

\begin{tabular}{ll}
\hline Specialty & $\begin{array}{l}\text { No (\%) of } \\
\text { admissions }\end{array}$ \\
\hline Surgery and orthopaedics & $61(37 \cdot 65)$ \\
Medicine & $47(29 \cdot 0)$ \\
Cardiology & $13(8 \cdot 0)$ \\
Cardiovascular surgery (postoperative) & $6(3 \cdot 7)$ \\
Otolaryngology & $17(10 \cdot 5)$ \\
Neurosurgery & $15(9 \cdot 3)$ \\
Neonatology & $3(1 \cdot 85)$ \\
\hline
\end{tabular}


intensive care unit, on a scale of 1 to 4 . For example, a score of one point is awarded for the necessity for a single intravenous line or for the provision of chest physiotherapy, and the use of peritoneal dialysis or intracranial pressure monitoring scores four points for each. All treatments other than extracorporeal membrane oxygenation and the use of the intra-aortic balloon pump were available in our unit. One modification was made for young patients by allocating three points for administration of blood products in excess of $20 \%$ total blood volume per 24 hour period. The Physiologic Stability Index 912 was scored for class 4 patients simultaneously with the TISS scores. The Physiologic Stability Index is a physiologically based classification designed to assess objectively the severity of illness of paediatric patients. Thirty four variables with limits assigned depending on age and clinical importance are scored $0,1,3$, or 5 . For example, a heart rate of 180 beats per minute is scored one point in an infant or three points in an older child and a urine output of $0.5 \mathrm{ml} / \mathrm{kg} /$ hour is scored one point and three points if less than this. The most abnormal value per 24 hours is used for scoring and daily scores derived by summing the individual scores.

Scores for all patients were determined by the same observer (JMcA) for consistency of assessment. The mean TISS scores/patient/day for clinical class, management goal, and age groups were calculated. Admission, mean and maximum TISS and physiologic stability scores were also calculated for class 4 survivors and non-survivors. Survival was defined as surviving to discharge from the unit. Days of intensive care were recorded for each individual and resource utilisation for the described categories estimated from the total days in the intensive care unit and TISS scores/patient/day. ${ }^{10}$

Comparison between group means was by Student's $t$ test. As durations of stay were not normally distributed the Mann-Whitney U test was used for comparisons. Mortality numbers were compared by $\chi^{2}$ analysis, $\chi^{2}$ with Yates's correction or Fisher's exact test as appropriate.

\section{Results}

There were 162 consecutive admissions during the eight month study period with stays ranging from 1-94 days (median 3). A total of 133 (82\%) survived to be discharged from the unit and no child died within one month of discharge. Physiologically unstable patients (class 4) comprised $50 \%$ (table 2). Mortality was inversely related to clinical class with all class 2 patients surviving. Resource utilisation in terms of days in the intensive care unit and TISS scores were significantly different between the four classes of patients. The mean (SEM) TISS score for the 24 hour period before discharge for survivors was $13.42(0 \cdot 66)$.

\section{GOAL OF TREATMENT}

Therapeutic intention was curative for the majority $(101,62 \cdot 3 \%)$ of children and palliative no option for $30(18 \cdot 5 \%)$. Five children were admitted to avail of the intensive care unit monitoring facilities such as continuous radial artery pressure recording. The mean (SEM) TISS scores, $21.72(1 \cdot 17)$ in the curative group, $18.43(1.45)$ in the palliative no option group, and $17.57(1.6)$ in the palliative option group, were not significantly different (table 3 ). There was also no difference between the groups for length of stay or rates of survival.

AGE

The majority of the children $(102,62 \cdot 9 \%)$ were age 12 months or less (neonates and infants); this included 33 neonates. The remaining 60 children were aged up to 15 years.

The neonatal group had primarily surgical problems except for three babies with respiratory distress admitted because no local special care baby unit cots were available. Neonates had the longest stay in the unit and older children the shortest (table 4). TISS scores were also higher for neonates than infants. Consequently resource utilisation was greatest for the neonates and less for older children. Survival rates were not significantly different between the groups.

Table 2 Comparison of clinical classes

\begin{tabular}{|c|c|c|c|}
\hline & $\begin{array}{l}\text { Class } 2 \\
(n=28)\end{array}$ & $\begin{array}{l}\text { Class } 3 \\
(n=53)\end{array}$ & $\begin{array}{c}\text { Class } 4 \\
(n=81)\end{array}$ \\
\hline $\begin{array}{l}\text { Median (range', suiv (days)* } \\
\text { Mean (SEM) TISS score/patient/dayt } \\
95 \% \text { Confidence interval } \\
\% \text { Survival }\end{array}$ & $\begin{array}{l}2(1-4) \\
7 \cdot 18(0 \cdot 64) \\
5 \cdot 87 \text { to } 8 \cdot 5 \\
100 \cdot 0\end{array}$ & $\begin{array}{l}2(1-12) \\
16 \cdot 62(0 \cdot 96) \\
14 \cdot 73 \text { to } 18 \cdot 5 \\
92 \cdot 4\end{array}$ & $\begin{array}{l}6(1-94) \\
26 \cdot 48(1 \cdot 09) \\
24 \cdot 35 \text { to } 28 \cdot 6 \\
69 \cdot 1\end{array}$ \\
\hline
\end{tabular}

${ }^{*} \mathrm{p}=0.01$ between all classes; $\mathrm{tp}<0.001$ between all classes.

Table 3 Comparison of therapeutic goals

\begin{tabular}{|c|c|c|c|c|}
\hline & $\begin{array}{l}\text { Curative } \\
(n=101)\end{array}$ & $\begin{array}{l}\text { Palliative } \\
\text { no option } \\
(n=30)\end{array}$ & $\begin{array}{l}\text { Palliative } \\
\text { option } \\
(n=26)\end{array}$ & $\begin{array}{l}\text { Monitored } \\
(n=5)\end{array}$ \\
\hline \multirow{2}{*}{$\begin{array}{l}\text { Median (range) stay (days)* } \\
\text { Mean (SEM) TISS score/ } \\
\text { patient/day* } \\
95 \% \text { Confidence interval } \\
\% \text { Survivors* }\end{array}$} & $4(1-58)$ & $2(1-94)$ & $4 \cdot 5(1-41)$ & $2(1-2)$ \\
\hline & $\begin{array}{l}21 \cdot 72(1 \cdot 17) \\
19 \cdot 4 \text { to } 24 \cdot 0 \\
81 \cdot 2\end{array}$ & $\begin{array}{l}18 \cdot 43(1 \cdot 45) \\
15 \cdot 58 \text { to } 21 \cdot 28 \\
76 \cdot 7\end{array}$ & $\begin{array}{l}17 \cdot 57(1 \cdot 6) \\
14 \cdot 3 \text { to } 20 \cdot 9 \\
88.5\end{array}$ & $\begin{array}{l}3.8(0.92) \\
1.26 \text { to } 6.34 \\
100.0\end{array}$ \\
\hline
\end{tabular}

No significant difference between curative and palliative groups. 
Table 4 Comparison of age groups

\begin{tabular}{|c|c|c|c|}
\hline & $\begin{array}{l}\text { Neonates } \\
(n=33)\end{array}$ & $\begin{array}{l}\text { Infants } \\
(n=69)\end{array}$ & $\begin{array}{l}\text { Others* } \\
(n=60)\end{array}$ \\
\hline $\begin{array}{l}\text { Median (range) stay (days) } \dagger \\
\text { Mean (SEM) TISS score/patient/day } \neq \\
95 \% \text { Confidence interval } \\
\% \text { Survivors } \int\end{array}$ & $\begin{array}{l}7(1-58) \\
23 \cdot 84(1 \cdot 54) \\
20 \cdot 81 \text { to } 26 \cdot 86 \\
78 \cdot 8\end{array}$ & $\begin{array}{l}3(1-94) \\
19 \cdot 37(1 \cdot 34) \\
16 \cdot 74 \text { to } 22 \cdot 0 \\
84 \cdot 0\end{array}$ & $\begin{array}{l}2(1-50) \\
18 \cdot 5(1 \cdot 45) \\
15 \cdot 6 \text { to } 21 \cdot 4 \\
81 \cdot 7\end{array}$ \\
\hline
\end{tabular}

Table 5 Comparison of class 4 patients for outcome (results are mean (SEM) and 95\% confidence interval (CI) except where shown otherwise)

\begin{tabular}{|c|c|c|}
\hline & $\begin{array}{l}\text { Survivors } \\
(n=56)\end{array}$ & $\begin{array}{l}\text { Nom-survivors } \\
(n=25)\end{array}$ \\
\hline $\begin{array}{l}\text { Median (range) stay (days)* } \\
\text { Admission TISS score* } \\
95 \% \text { CI } \\
\text { TISS score/patient/day† } \\
95 \% \text { CI } \\
\text { Maximum TISS scoreł } \\
95 \% \text { CI } \\
\text { Admission score for }\end{array}$ & $\begin{array}{l}7(2-58) \\
29 \cdot 9(1 \cdot 25) \\
27 \cdot 4 \text { to } 32 \cdot 4 \\
23.71(0 \cdot 99) \\
21.8 \text { to } 25 \cdot 6 \\
32.9(1.21) \\
30.5 \text { to } 35 \cdot 3\end{array}$ & $\begin{array}{l}4(1-94) \\
35 \cdot 04(2 \cdot 66) \\
29 \cdot 5 \text { to } 40 \cdot 5 \\
32 \cdot 19(2 \cdot 48) \\
27 \cdot 3 \text { to } 37 \\
39 \cdot 52(2 \cdot 47) \\
34 \cdot 7 \text { to } 44 \cdot 4\end{array}$ \\
\hline 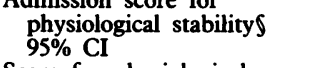 & $\begin{array}{l}10.39(0.75) \\
8.89 \text { to } 11.9\end{array}$ & $\begin{array}{l}16 \cdot 6(1 \cdot 76) \\
13 \cdot 0 \text { to } 20 \cdot 3\end{array}$ \\
\hline $\begin{array}{l}\text { Score for physiological } \\
\text { stability/patient/dayt } \\
95 \% \text { CI } \\
\text { Maximum score for }\end{array}$ & $\begin{array}{l}8 \cdot 41(0 \cdot 48) \\
7 \cdot 47 \text { to } 9 \cdot 34\end{array}$ & $\begin{array}{l}15 \cdot 85(1 \cdot 7) \\
12.51 \text { to } 19 \cdot 9\end{array}$ \\
\hline $\begin{array}{l}\text { physiological stability† } \\
95 \% \text { CI }\end{array}$ & $\begin{array}{l}15 \cdot 5(0 \cdot 77) \\
13.98 \text { to } 17 \cdot 01\end{array}$ & $\begin{array}{l}19 \cdot 54(1.56) \\
16.48 \text { to } 22 \cdot 59\end{array}$ \\
\hline
\end{tabular}

CLASS 4 PATIENTS

This group constituted half of all admissions. There was no significant difference between length of stay for survivors and non-survivors. There were significant differences between TISS scores and scores of physiological stability (table 5).

\section{Discussion}

This study provides the first prospective evaluation of therapeutic goals, severity of illness, and resource utilisation in a multidisciplinary paediatric intensive care unit in the UK. Comparison with the pooled European data highlights similarities and differences. ${ }^{4}$ No class 1 patients were admitted to our intensive care unit; however, this group comprised $6 \%$ of admissions to eight European units. ${ }^{4}$ The percentage admitted for observation (17.3\%) was the same as the European experience (17.5\%). The proportion of class 4 patients was high in comparison with the European average (39.5\%), although two units had $51 \%$ and $54 \%$ class 4 patients. The Clinical Classification System is a subjective classification but comparison of the mean (SEM) admission treatment scores of physiologically unstable patients in the two studies (31.51 $(1.21)$ in the UK compared with $26.04(11.3)$ in Europe) confirms that there was a real difference in admission patterns. This difference may be partly explained by the relatively small size of our unit for the population served. The demand for the beds is consequently usually high. However, it has also been our observation that when space is available there is a tendency for more physiologically stable patients to be admitted. Rothstein and Johnson in their study of an American multidisciplinary unit reported over $60 \%$ of admissions scoring less than 10 TISS points and having a mean stay of 1.6 days. ${ }^{13}$ They concluded that only patients with care requirements scoring $>10$ points require admission to an intensive care unit. The mean score for the $\mathbf{2 4}$ hours before discharge of live children in our study $(13.42)$ suggests that the unit was used relatively efficiently. However, Pollack et al reported higher last day TISS scores than us from a similar American unit. ${ }^{7}$ Unfortunately there is no transitional care unit in our hospital to which the children can be discharged and they must be sent directly to the wards. This situation encourages the consultant in the intensive care unit to delay discharge on occasions when the receiving ward has difficulty providing close observation for the child. During the study period no patient required readmission for collapse or died shortly after discharge demonstrating that the strategy is effective. This lack of an intermediate care facility partly explains the longer mean days in paediatric intensive care of sick patients in the UK $(10 \cdot 44)$ and Europe $(9 \cdot 1)$ compared with the US $\left(<5,,^{7} 6 \cdot 8,85 \cdot 5^{10}\right)$.

Resource utilisation was the same whether a cure was possible or not, reflecting similar levels of sickness between the groups. This also indicates that the responsible consultants had an optimistic approach to treatment and did not discriminate between patients on the basis of possible long term outcome. This approach has important implications for the provision and utilisation of services and resources other than those of the intensive care unit and is itself the subject of a complementary study in the unit addressing the long term consequences of intensive care provision. In terms of short term survival this approach is justified as there was no significant difference in the survival rates between the goal groups.

The majority of the children were 1 year or younger $(63 \%)$ as was the case in the European centres $(72 \%)$. This differs from American experience with most of the patients in the USA greater than 12 months old. ${ }^{7-10}$ This may reflect a preference not to admit neonates to these units. In our paediatric intensive care unit, neonates with respiratory disease are not usually admitted explaining the much higher proportion in European centres (37.2\%). Duration of stay was significantly greater for neonatal patients partly accounting for the shorter mean stay of all patients in American units. We confirmed the finding of Beaufils et al that TISS scores were also greater for neonates. ${ }^{4}$ Obviously the 
age mix of the population in the paediatric intensive care unit in addition to the availability of transitional care beds has important implications for the utilisation of available resources. The survival rates were the same for our age groups but mortality was greater for the neonates in the European study. This could be explained if the sickness levels in the European babies was greater than ours but comparison of the mean (SEM) admission TISS scores $(27.42(1.98)$ in the UK compared with 21.7 (11.87) in Europe) does not support this. However, this possibility cannot be completely ruled out as the maximum scores may have been greater in Europe but are not reported by Beaufils et al. ${ }^{4}$ It is also possible that the mortality figures reflect the different populations of babies with respiratory disease as there were only three babies $(1 \cdot 85 \%)$ in our unit with respiratory disease in contrast to $56 \%$ of European neonates.

Our overall death rate $(17.9 \%)$ was higher than in Europe $(12.5 \%)$ but the comparison is more favourable when allowance is made for severity of illness $(21.6 \%$ in the UK compared with $18.9 \%$ in Europe for classes 3 and 4 ). Among the sickest patients there were significant differences for mean and maximum TISS and physiological stability scores between survivors and non-survivors. This has been reported previously. ${ }^{4}{ }^{7-9}$ Schleffler et al demonstrated a complex relationship between survival and the level of therapeutic intervention in adults. ${ }^{14}$ They observed that initially the probability of survival increases directly with the level of intervention and then decreases at the highest level of intervention, posing the dilemma that intervention can prolong life in the short term. We found no difference in stay in the intensive care unit between survivors and non-survivors and higher maximum scores than admission scores, confirming that the observation of Schleffler $e t a l$ is equally valid for paediatric illnesses. As more resources are utilised by nonsurvivors the cost of their care is consequently greater. Our admission scores did show significant differences in points for physiological stability for outcome but not for TISS scores and two of the 11 patients who ultimately received treatment scoring 50 or more TISS points survived. Unfortunately there is no mortality predictor score available with the sensitivity to guide individual decision making ${ }^{15}$ and efficiency of paediatric intensive care should not be maximised by patient selection on the basis of outcome.

In conclusion, the interest shown in paediatric intensive care in the UK has not been complemented by substantial evaluation. This study provides data that characterise the population of a typical multidisciplinary paediatric intensive care unit in terms of treatment options, sickness levels, resources utilised, and outcome. This information is important because not only is it necessary for meaningful clinical audit of ongoing activity within the unit but it also provides a basis for interunit comparisons of standards of care and outcomes. More information is essential and will be required by health service managers if the government's plans for competitive tendering of hospital services becomes a reality.

This work was funded by a DHSS research fellowship. We thank the nursing and junior medical staff of the intensive care unit, the nursing and junior medical staff of the intensive care unit, Royal Belfast Hospital for Sick Children, for all their help in data
collection and the consultants for allowing us to report on their patients.

1 Farman JV. Paediatric intensive care units. Lancet 1987;ii: 894.

2 Heaf BP. Organisation of paediatric intensive care. Care of the Critically Ill 1986;2:141-2.

3 Committee on hospital care and the paediatric section of the society of critical care medicine. Guidelines for paediatric intensive care units. Crit Care Med 1983;11:753-60.

4 Beaufils F, Roze JC, Azema D, et al. Evaluation of Pediatric intensive care in Europe. A collaborative study of the European Club of Pediatric Intensive Care. Intensive Care Medicine 1987;13:65-70.

5 Beaufils F. L'evaluation en reanimation pediatrique. Arch Fr Pediatr 1984;41:229-36.

6 Civetta JM. The inverse relationship between cost and survival. f Surg Res 1973;14:265-9.

7 Pollack MM, Yeh TS, Ruttimann UE, et al. Evaluation of pediatric intensive care. Crit Care Med 1984;12:376-83.

Yeh TS, Pollack MM, Holbrook PR, et al. Assessment of pediatric intensive care-application of the therapeutic pediatric intensive care-application of the therapeutic
intervention scoring system. Crit Care Med 1982;10: intervention $497-500$.

9 Yeh TS, Pollack MM, Ruttimann PR, et al. Validation of a physiologic stability index for use in critically ill infants and children. Pediatr Res 1984;18:445-51.

10 Glass NL, Pollack MA, Ruttimann UE. Pediatric intensive care: who, why and how much. Crit Care Med 1986;14: 222-6.

11 Keene RA, Cullen DJ. Therapeutic intervention scoring system: Update 1983. Crit Care Med 1983;11:1-3.

12 Georgieff MK, Mills MM, Bhett P. Validation of two scoring systems which assess the degree of physiologic instability in critically ill newborn infants. Crit Care Med 1989;17:17-21.

13 Rothstein PR, Johnson PJ. Pediatric intensive care: factors that influence outcome. Crit Care Med 1982;10:34-7.

14 Schleffler RM, Knaus WA, Wagner DD, et al. Severity of illness and the relationship between intensive care and illness and the relationship between intensive
survival. Am f Public Health 1982;72:449-54.

15 Lemeshow S, Teres D, Spitz Avrunin J, et al. A comparison of methods to predict mortality of intensive care unit patients. Crit Care Med 1987;15:715-22. 